DOI: 10.12731/2227-930X-2017-3-64-84

УДК 334.012.23

\title{
МОДЕЛЬ ЧЕЛОВЕКА \\ ИНСТИТУЦИОНАЛЬНОГО В ТЕОРИИ И ИДЕОЛОГИИ СОЦИАЛЬНО ОТВЕТСТВЕННОГО БИЗНЕСА РОССИИ
}

\author{
Шулимова $A . A$.
}

Экономическое обоснование мотивации социальной активности коммерческой структуры представлено в аналитической модели человека. В российской экономической науке исторически сложилось, что традиционные формы сочиальной ответственности бизнеса анализируются в рамках православной модели «человека институционального». Современная идеология социально ответственного бизнеса воспроизводит в секуляризированном виде институциии социальной ответственности православного предпринимателя. Ментальнье основания корпоративной филантропии в сущностных характеристиках корреспондируются с православным традицияи взаимопомощи и делового сотрудничества. В ракурсе эволюичонного усложнения института социальной ответственности бизнеса воспроизводство базовых элементов православной модели человека институционально расширяют адаптационные возможности субъектов корпоративного предпринимательства к конкурентной среде международного бизнеса.

Цель - выявление сущностных характеристик модели «человека институционального», имплицитно представленной в теории и идеологии социально ответственного бизнеса России.

Метод или методология проведения работы: в статье использовался метод диалектики, системный подход, применялся принщип историзма, а также методологический инструментарий эволюционной экономической теории.

Результаты: аргументировано, что модель «человека институциионального», имплицитно представленная в теории и идеологии социильно ответственного бизнеса России, в значительной 
степени закрепляет преемственность поведенческих установок современного предпринимателя с православной моделью человека, воспроизводимой в предпринимательском сообществе дореволюцчионной эпохи.

Область применения результатов: полученные результаты цуелесообразно применять при осущуествлении соцуиального инвестирования, разработке мероприятий по реализацчии соцчиального партнерства и программ повыпения информационной открытости российского бизнеса.

Ключевые слова: сочиальная ответственность бизнеса; экономическая модель человека; экономическая идеология; православная модель человека; корпоративная филантропия.

\section{HOMO INSTITUTIUS MODEL IN THE THEORY AND IDEOLOGY OF SOCIALLY RESPONSIBLE BUSINESS IN RUSSIA}

\section{Shulimova A.A.}

Consistent to the earlier research, the study has supported the hypothesis that the investigation of motivation of commercial body social activity in the economic theory expressed in analytical model of man. The author emphasizes the idea that the main principles of well-formulated statement of traditional form of social responsibility of business are given in the Christian Orthodox model of man. The new ideology of socially responsible business is represented in secular forms of social responsibility of a Christian Orthodox entrepreneur. Mental models of corporate philanthropy in their core characteristics correspond to Christian orthodox traditions of mutual aid and business collaboration. From the point of view of the evolutionary and institutional economics, additional advantages of modern corporates can be acquired by integrating basic elements of the Orthodox model of man in their structures.

Purpose. The purpose of the study was to identify the significant elements in the model of homo institutius. It is the assumption that mod- 
ern theory and ideology of socially responsible business in Russia is an important result of development of religion ideas that is the implicit element of this model.

Methodology. For the aims of the article, the systematic method, historicism and dialectical approaches, as well as the analytical technique of evolutionary economics were used.

Results. The author has proved that a sufficient degree of the adaptive efficiency of a modern corporation can usually be enhanced by using historically generated elements of the homo institutius model.

Practical implications. The results can be applied in corporate management to improve social investment and social partnership business programs as well as to increase openness of firms.

Keywords: social responsibility of business; economic model of man; economic ideology; Orthodox model of man; corporate philanthropy.

\section{Введение}

Теория социально ответственного бизнеса России в настоящее время находится в стадии формирования. Российские и зарубежные исследователи разрабатывают теоретико-методологический аппарат исследований альтруистических форм экономического поведения фирмы в институциональной среде современного рыночного хозяйства [19]. В предметное поле современной экономической теории включаются проблемы социальной эффективности хозяйственной деятельности, что связано с тем обстоятельством, что предпринимательство в настоящее время престало быть исключительно сферой своекорыстных интересов и коммерческих мотивов. Современный социальный порядок не устанавливает четкого разграничения индивидуального и социального в мотивации человеческой деятельности. А, значит, в экономической теории, как и в обыденной жизни, весьма трудно разграничить побуждения эгоистического и альтруистического характера.

В качестве центральной методологической установки следует принять исследовательскую предпосылку институциональной 
теории, что системы убеждений трансформируются в экономические структуры посредством институций [24, р. 363]. В качестве исходных институций социальной ответственности выступают институции благотворительности, меценатства, социального служения. Институциональный прототип социальной восприимчивости субъекта встроен в его мотивационную структуру через религиозную традицию доброжелательности и альтруизма, воспроизводящую координирующую функцию идеологии [21, p. 173].

В современном обществе на основе воспроизводства институций социальной ответственности конструируется деятельность некоммерческих организаций [23, p. 245]. В частности, институции взаимной поддержки крестьянских (фермерских) хозяйств воспроизводятся в формате ассоциаций или союзов фермерских хозяйств, образованных по территориальному и/или отраслевому признакам, через координацию их «предпринимательской деятельности, представления и защиты общих имущественных интересов» [11].

\section{Православная модель «человека институционального»}

Базовые элементы православного вероучения прямо и опосредованно формируют идеологические конструкции социальной восприимчивости субъектов предпринимательства. В предпринимательской деятельности «наряду с другими духовными типами, существует и христианский тип еconomic man - как в самом общем смысле, так и более конкретно, применительно к разным христианским исповеданиям» [2, с. 345-346]. В ракурсе институциональной экономики исследуется отношения человека к человеку как аспекты социального обеспечения производственной деятельности, согласования производства и потребления [27, p. 835]. В православной модели человека социальное обеспечение хозяйственной деятельности представляют институционализированные православной церковью обычаи и традиции, которые в экономической практике становятся реальной силой, управляющей человеческим поведением. Человек, ориентированный на православие, в своей повседневной хозяйственной деятельности выступает аген- 
том института русского православия. Следовательно, для данной теоретической конструкции, более уместно обозначение православной модели человека институционального - homo institutius. A, значит, экономическое поведение православного актора определяется институциональной логикой действий, которая задает мотивы и цели, побуждает население к экономической активности [18, с. 104].

Модель человека институционального исходит из установки, что предпочтения в ситуации экономического выбора не являются экзогенными, а скорее обусловлены экономическими и социальными взаимодействиями в повседневной жизни [12, с. 133-137]. Сложность рассмотрения православного человека институционального заключается в сопряженности вопросов хозяйственной этики с проблематикой богословия.

В фокусе внимания экономистов, конструирующих модели человека институционального, находятся вопросы рациональности и экономической культуры, концептуальные и статические характеристики деловых и профессиональных взаимодействий [17, p. 343]. Религиозная форма вовсе не «вымывает» экономического содержания из ценностей, убеждений и мнений агентов православия. Эти институциональные атрибуты представляются важнейшим источником информации о поведении человека в ситуации экономического выбора [26, p. S. 222].

Важнейшая социальная функция институтов религии - упорядочивание сознания человека. Сакрализованный религией, моральный код сообщества, способствует поддержанию чувств солидарности и симпатии. В эволюционной перспективе в сообществе, где присутствуют индивиды, способные на самопожертвование, имеются преимущества в борьбе за выживание [20, p. 90]. В конкретном исторической реальности альтруизм обеспечивается благодаря духовной дисциплине, идеологической системе внушений, санкций и моральных принципов, которые призваны стимулировать чувства долга и обязательств, предоставляя человеку нечто вроде опоры из представлений, помогающих ему организовать 
экономическое мышление [14, с. 70]. На основе религии формируется символический капитал человека как важнейшая форма культурного капитала. В институциональных исследованиях обосновывается тезис, что высокий уровень накопления культурного капитала может уменьшить неопределенность и породить конкретное отношение к будущему, ведь экономическая культура предусматривает предсказуемый отклик на спонтанные эмоции человека [22, р. 90]. Коммерциализируя, накопленные элементы культурного капитала, предприниматели будут располагать широким арсеналом решений по вопросам имиджа и брендинга.

Православное ви́дение хозяйства, представленное в работах идеологов и подвижников православия на разных исторических этапах, демонтируют широкий диапазон жизненных практик от мироотреченности до обмирщения. Универсальные черты христианского верования - личная заслуга, личная ответственность человека перед Богом [13, с. 104]. Особые черты православного человека институционального обозначились исходя из отличительных особенностей русского православия в его конкретных исторических условиях.

Сущностные характеристики, раскрывающие модель homo institutius в динамично изменяющемся экономическом пространстве, содержатся в разрозненных элементах бытия, отделение от воспроизводства которых приводит к деструкции вменяемого статуса. В русской православной культуре подобные характеристики присущи институции бытового исповедничества, которая в трактовке Н.С. Трубецкого определяется как «пропитанность культуры и быта религией» [10, с. 264].

В аспекте новейших исследовательских задач экономической теории единицей экономического анализа становится социально ответственная личность. Формы и уровень ответственности определяется эндогенными ограничителями, в числе которых важную роль занимают правила человеческого общежития, выработанные религией. В качестве стержневых характеристик православной модели социально ответственной личности выступают следующие элементы православного вероучения и житейской практики: 
- идеал спасения как основа целеполагания и индивидуального выбора [8, с. 26];

- соборный идеал, основанный на абсолютизации отношений, складывающихся в локальном сообществе, организованных по принципам патриархальной семьи братского типа [12, с. 137];

- концепция утешения и посмертной компенсации невзгод как идеологическая основа формирования ценностей трудолюбия и бережливости [5, с. 155-167];

- свобода индивидуального выбора между добром и злом [8, с. 27];

- возможность покаяния и изменения положения в координатах духовного развития;

- теория «казней божиих» как должного воздаяния за грехи или символического знака, с помощью которого стихийные бедствия и катастрофы побуждают человека задуматься о правильности своего жизненного пути;

- стремление к отречению от мирской суеты, предпочтение аскетичного устава семейной и домашней жизни [5, с. 157];

- широта души - «стихийность и страстность, не сдерживаемая достаточной волей и дисциплиной» [5, с. 156];

- увлечение паломничеством (странничеством) - хождением на богомолье по святым местам и монастырям;

- культовое благочестие, обрядоверие [7, с. 211];

- технологический консерватизм;

- нахождение в основе русского православного самочувствия добродетели смирения [5, с. 165], и как следствие терпение в страданиях;

- признание души наивысшей ценностью светской культуры и религиозного искусства $[8$, с. 23-31];

- перенесение идеи самодержавия из религиозно-философской сферы в сферу социально-политической экономической мысли;

- способность к созерцанию и восприятию окружающего мира; 
- признание кротости и простаты души в качестве высшей добродетели;

- символическое уподобление излишнего рвения в мирской трудовой деятельности и деловой сфере «дьявольскому искушению» [13, с. 109];

- разделение образа жизни на праведный, трактуемый как образец для подражания, и греховный, трактуемый как предмет осуждения [2, с. 78];

- панорамное зрение - Божественный небесный масштаб видения жизни.

Православное вероучение отрицательно относится к любым проявлениям принуждения к вере. Нравственное самосовершенствование признавалось духовно ценным и целесообразным в случае, если оно совершалось на добровольной основе [10, с. 298]. Русская христианская традиция сформировалась в формате народного мировосприятия. С периода Древней Руси проповедь была «простодушной», ориентировалась на духовные нужды простого человека.

Православная традиция социальной восприимчивости в эволюционных параметрах российской цивилизации санкционировала эндогенные институции социальной ответственности - добросовестное деловое сотрудничество, уважение к правам частной собственности и т. п. В русской народной традиции взаимопомощь основаны на здравом смысле и опыте человеческого общежития в тех суровых природно-климатических условиях, в которых складывалась российская государственность.

\section{Православные традиции социальной активности бизнеса и адаптивная эффективность современного предпринимательства в России}

Идеологической основой социальной ответственности в России с момента официального принятия христианства становятся библейские нормы милосердия и благотворительности, а также укоренившиеся в сознании экономические институты христи- 
анства - система норм, правил и ценностей, структурированных церковным учреждением, обуславливающих возможность организации хозяйственной жизни на универсальных принципах человеческого сотрудничества.

Вектор развития рыночной экономики предопределяют стимулы и мотивации предпринимательского сообщества, опосредованные социальной этикой. Причем, «этические принципы как интернализация идеала, заложенного в основу рыночной координации», [6, c. 80] формируют материальную самобытность человека, которая проявляется в процессе принятия индивидуальных решений. Специфика религиозных традиций задает параметры социальной стратификации и возможности модернизации экономических систем, что особенно проявляется в периоды трансформаций [29, р. 462].

В деловых кругах дореволюционной России существовала давняя традиция позиционировать себя в качестве агента религиозных институций. Так, православный крестик в начале делового письма в Древнем Новгороде символизировал христианскую инвокацию его автора [4, с. 131]. В условиях персонифицированных обменов знаки «взывания к имени Божьему» выполняли функцию фокальных точек, повышающих вероятность кооперативных действий людей, принадлежащих к христианской религии.

Религия, как и семья и гражданское общество, социализируют мотивированного личным интересом человека, заставляют его учитывать последствия своих решений на поведение других людей. Очевидно, что ментальные конструкции религии могут служить каналом экономических действий. Когнитивная и мотивационная роль в формировании экономической дисциплины наиболее ярко прослеживается в идеологических институтах. Они формируют актуальное соотношение реальности и ценностей. Религиозное мировоззрение определяет траекторию действий, в рамках которых осуществляется согласование материальных и нематериальных интересов. В современных экономических исследованиях показано, что религиозные страхи, в частности, вера в ад, формируют позитивные мотивацион- 
ные установки. В то время как вера в рай и посмертное существование ослабляет мотивацию к экономической активности $[1$, c. 88$]$.

Вектор духовного саморазвития человека определялся теми идеальными образами, которые представлены в духовно-учительной литературе - образами православных святых и библейских героев. Так, аскетический идеал спасения органично дополнялся идеалом спасения через жизнь и покаяние в миру, через подвижничество в трудовой сфере. Предпочтение к мирской аскезе и трудовой дисциплине органично присуще православному человеку. Если не учитывать демотивирующее воздействие на поведение человека, которое оказывают идеи послушания, транслируемые религией $[15$, p. 100], то православную этику хозяйствования можно рассматривать как позитивный фактор экономической активности.

Важнейшей характеристикой институциональной модели человека представляется чувство справедливости, которое формирует экономический порядок в обществе. Справедливость в институциональных исследованиях нередко предстает «в качестве законодателя с ограниченной властью поддержания существующих обычаев» [16, р. 37]. В религиозных институциях поддержание социального порядка осуществляется через идентификацию греха. Согласно духовной православной традиции за всякий неисповеданный грех душа будет «истязаться на мытарства», поэтому в церковной литературе приводятся длинные перечни грехов, которые периодически «поновлялись» и дополнялись.

Важнейшая характеристика современной предпринимательской деятельности - принятие риска, в том числе социального. Понятие «риск» в общественном сознании тесно связано с идей вероятности, фортуны, опасности, восприятием предназначенного и случайного. В традиционном обществе религиозные учения, как формы верований и кодексы ритуальных действий, обеспечивали провиденциальную интерпретацию человеческой жизни. Православная символика в Российской империи сопровождала все обряды перехода человека в новый социальный статус. Рождение чело- 
века освещалось таинством крещения, свадьба - таинством брака, похороны - христианским ритуалом погребения. Вера в бога смягчала восприятие неудач, формировала среду доверия в обществе единоверцев. В русском православии механизмом минимизации социального риска служила идея божественного наказания и человеческого покаяния. О распространенности покаяния как мистического способа исправления дел в древнерусском обществе свидетельствуют многочисленные молитвенные записи писцов, художников и переплетчиков древнерусских пергаменных кодексов. Причем, просьбы о божественном прощении нередко представлены в одной записи с просьбой о божьей помощи.

Склонность к хозяйственному расчету и учету проданной, купленной и произведенной продукции появляется в модели человека православного, как только монастыри стали теснее контактировать с населением через посредничество рынка. Регулярное ведение приходно-расходных книг и их контроль в непростую эпоху Ивана Грозного позволили нейтрализовать высокие политические и хозяйственные риски и сохраниться монастырской экономики. Тогда же в монастырях появляется новый тип человека - человека способного справиться со сложными инженерными задачами, усовершенствовать орудия труда, организовать строительство инженерных сооружений [3, с. 157].

Бережливость, как важнейший элемент финансовой грамотности, в условиях современного финансового кризиса - далеко не единственное условие достижения оптимального баланса между экономической эффективностью, социальной справедливостью и свободой индивидуального выбора. Для эффективной саморегуляции рынка необходим дополнительный арсенал моральных ценностей и качеств человека как субъекта коллективных действий. Наиболее значимые среди них - критицизм мышления, предосторожность, тяга к знаниям, «бескорыстный и восторженный дух», толерантность, независимость и т. п. [28, р. 498-499].

В экономической теории важнейшей социальной функцией религии представляется преодоление индивидуального эгоизма, 
генетическое обоснование моральных чувств. Частная благотворительность - одна из наиболее распространенных религиозных практик, оцениваемая как внешнее проявление ответственности перед Богом и обществом, обозначавшее символическую принадлежность к православию. Идеологическая основа православной концепции благотворительной функции богатства - заповедь нищелюбия, любостяжательство через праведное использование богатства. Благотворительность как норма поведения богатого человека была воспринята еще в Киевский период согласно христианскому призыву «Благотворящий бедному дает взаймы богу» [14, с. 73].

С развитием рынка и расслоением общества в конце XIX - начале XX вв. благотворительность становится механизмом корректировки идеологии индивидуализма. Эгоистические мотивы хозяйства смягчались ритуальными акциями христианского милосердия, осуществляемыми к своим ближним, преимущественно в воскресные дни. Как известно, социальная сегментация и коллективное пользование ресурсами способствует распространению индивидуального альтруизма, а конфликты между социальными группами играют ключевую роль в поддержании альтруистических моделей поведения. В капиталистической России в качестве катализаторов альтруизма предпринимателей представляется борьба с иностранными конкурентами и совместное использование идеологических ресурсов русского православия.

Следует отметить влияние институтов социальной ответственности на экономический выбор предпринимателей, ориентированных на ценности православия. В институционально-экономических исследования неоднократно обосновывалась идея о том, что одним из важнейших факторов капиталистического развития является религиозная мысль [25, р. 188]. Исторически сложилось, что институты религии оказывали существенное влияние на создание норм и принципов престижного потребления, распространенных в обществе на каждом этапе эволюции, в том числе в капиталистическую эпоху. 
В России нормы престижного потребления предусматривают расходы на благотворительность и пожертвования на нужды церкви. В современных условиях принцип подаяния внедрен в механизм финансового обеспечения православных приходов и приходского духовенства. Скудное обеспечение, по существу, нищенство дает экономическое основание для обращения представителей приходов, особенно сельских, для просьб со стороны их духовенства о финансовой помощи к миру.

В индустриальных обществах доминирует предпринимательская и обывательская (потребительская) культуры, которые постепенно теряют религиозную «окраску». Религия опосредованно воздействует на национальную этику хозяйства. Мировоззренческими основаниями экономической мотивации представляются ментальные модели достижения жизненных целей и системы жизненных координат верующих (таблица 1).

Таблицุа 1.

Институциональный механизм русского православия

\begin{tabular}{|c|l|}
\hline $\begin{array}{c}\text { Институциональные } \\
\text { характеристики }\end{array}$ & \multicolumn{1}{|c|}{ Содержание } \\
\hline Основания & $\begin{array}{l}\text { Вера, базирующаяся на догме, страсть (религиозный } \\
\text { пыл) и таинство }\end{array}$ \\
\hline Религиозные цели & $\begin{array}{l}\text { Спасение, блаженство, душевное успокоение, пра- } \\
\text { ведность и святость (особенно актуально для свя- } \\
\text { щеннослужителей) }\end{array}$ \\
\hline Санкции & $\begin{array}{l}\text { Тайная епитимия (поклоны, покаянные молитвы, тай- } \\
\text { ный пост, раздача милостыни, отказ от спиртного), пу- } \\
\text { бличное взыскание (отлучение от причастия, стояние } \\
\text { во время службы вне храма или в притворе), крайняя } \\
\text { мера анафема - отлучение от церкви и проклятие }\end{array}$ \\
\hline Религиозные средства & $\begin{array}{l}\text { Таинства, пастырское слово и проповедь, назида- } \\
\text { тельные примеры, канонизация святых, дидактиче- } \\
\text { ская литература поучения }\end{array}$ \\
\hline
\end{tabular}

Таблица составлена автором.

Отменив стремление к социальной гармонии, присущее институтам церкви, следует предостеречь от чрезмерной его идеализа- 
ции. Будучи господствующей идеологической системой, христианство не смогло остановить постоянные войны и грабежи, застой в земледельческой отрасли, голод и бедность народных масс. К тому же, в институциональном поле любой религии присутствует сдерживающий фактор экономического роста. К подобным ограничителям ответственного поведения следует отнести:

- угрозы религиозной или конфессиональной дискриминации в отношении лиц, представляющих религиозные меньшинства. Религиозная принадлежность может рассматриваться, как решающий фактор при приеме на работу, выборе поставщика или делового партнера. В этом качестве религиозная идентичность создает препятствия к сотрудничеству и дружественным соглашениям, формирует конфликтные ситуации на рабочем месте, в деловой сфере;

- приоритет интуитивных управленческих и экономических решений над рациональными;

- демотивация и предпочтения временной безработицы по религиозным убеждениям;

- в ситуации религиозного фанатизма: поддержка институтов традиционной экономики, которые формируют анти-стимулы для продуктивной хозяйственной деятельности, создают организации и группы давления, заинтересованные в поддержании существующих ограничений;

- использование православной символики продукции в качестве рекламной уловки;

- конфликт между христианской ортодоксией и научно-техническим прогрессом.

Религиозные ограничения оказывают положительное воздействие на факторы развития бизнеса, когда проявляется диалектика ограничения и освобождения, присущая религии. Международный стандарт корпоративной социально ответственности ИСО 26000 призывает «при взаимодействии с сообществом признавать и надлежащим образом принимать во внимание его характеристики религии» [9]. 
В России, как и в развивающихся странах, формальные и неформальные способы формирования социальной восприимчивости бизнеса проявляют чувствительность к религиозному контексту. Дух и практика корпоративной социальной ответственности часто сильно резонирует с традиционными ценностями и в неявном виде воспроизводит существенный массив поведенческих рутин, сгенерированных религиозными концепциями. Инвестиции в социальные проекты производятся с целью оптимизации нравственной и эстетической сторон корпоративной культуры и корпоративного бренда.

\section{Заключение}

В современных условиях воздействие институтов религии особенно заметно в отношении моральной ответственности бизнеса, где религиозные паттерны встраиваются в этические кодексы корпораций, профессиональных групп и предпринимательских сообществ. Благотворное воздействие религии на формирование нравственных начал в сфере бизнеса проявляется при условии толерантности и религиозной терпимости.

Православная модель человека восходит к нравственно-идеологическим установкам, актуальным для феодального хозяйства. В период капиталистической трансформации в этику хозяйства внедрялся философский идеал софийности и соборности, который преимущественно разрабатывался в трудах богословов. Экономическое учение русского православия, представляя морально-этический взгляд на экономические процессы и явления, формирует духовно-мировоззренческие основы развития народного хозяйства России. Сопоставление хозяйственно-этических установок русской православной церкви и моральных ограничений, господствующих в российской экономике, позволяет обосновать авторское мнение, что институты русского православия формируют нравственные ориентиры, благоприятствующие развитию социальной ответственности современного бизнеса. 


\section{Список литературы}

1. Борисова Е., Кулькова А. Культура, имена и экономическое развитие // Вопросы экономики. 2016. № 1. С. 81-106.

2. Булгаков С.Н. Православие. Очерки учения православной церкви. М.: Терpa, 1991. 416 c.

3. Зимин А.А., Хорошкевич А.Л. Россия времени Ивана Грозного. М.: Наука, 1982. 184 с.

4. Иншаков О.В., Фролов Д.П. Эволюция институционализма в российской экономической мысли (IX-XXI вв.). Т. 1. М.: Экономистъ, 2007. 511 c.

5. Карташев А. В. Церковь, история, Россия: статьи и выступления. М.: Пробел, 1996. С. 155-167.

6. Козловски П. Принципы этической экономии. СПб.: Экономическая школа, 1999. 344 с.

7. Костомаров Н.И. Очерк домашней жизни и нравов великорусского народа в XVI и XVII столетиях. СПб.: Типография К. Вульфа, $1860.215 \mathrm{c}$.

8. Митрополит Смоленский и Калининградский Кирилл. Русская православная церковь в современной России: служение обществу, трудности возрождения // Вопросы экономики. 2002. № 1. С. 23-31.

9. Руководство по социальной ответственности. ГОСТ Р ИСО 260002012. Издание официальное. М.: Стандартинформ, 2014. 126 с.

10. Трубецкой Н.С. Избранное. М.: РОССПЭН, 2010. 616 с.

11. Федеральный закон от 11.06.2003 N 74-Ф3 «О крестьянском (фермерском) хозяйстве» [Электронный ресурс]. Режим доступа: http:// www.consultant.ru/document/cons_doc_LAW_42662/

12. Шулимова А.А. Модель социально ориентированной рыночной экономики в экономическом учении русской православной церкви // Развитие социальной сферы: региональный взгляд. Краснодар: ИЭиУ МиСС, 2008. С. 133-137.

13. Шулимова А.А. Православная этика хозяйствования и «дух социального капитализма» // Социально-гуманитарный вестник: Bceроссийский сборник научных статей. Краснодар: ЦНТИ, 2010. C. 104-110. 
14. Экономические исследования: анализ состояния и перспективы развития / Под общей редакцией доктора философских наук, профессора О.И. Кирикова. Воронеж: ВГПУ, 2007. С. 70-78.

15. Adkisson R.V. Quantifying Culture: Problems and Promises / R.V. Adkisson // Journal of Economic Issues, 2014, vol. 48, no. 1, pp. 89-108.

16. Ambrosino A.A Cognitive Approach to Law and Economics: Hayek's Legacy // Journal of Economic Issues, 2014, vol. 48, no. 1, pp. 19-48.

17. Coleman S. Economy and religion / S. Coleman // A Handbook of Economic Anthropology / J. G. Carrier (Ed.), Cheltenham: Edward Elgar, 2005, pp. 339-352.

18. Dequech, D. Logics of Action, Provisioning Domains, and Institutions: Provisioning Institutional Logics // Journal of Economic Issues, 2013, vol. 47, no. 1, pp. 95-112.

19. Frolov D.P., Shulimova A.A. The evolution of socio-responsible business in developing countries: an institutional perspective // Life Science Journal, 2014, vol. 11, no. 11, pp. 562-566.

20. Hodgson G.M. The evolution of morality and the end of economic man // Journal of Evolutionary Economics, 2014, vol. 24, no. 1, pp. 83-106.

21. Hustinx L., Lammertyn F. Collective and Reflexive Styles of volunteering: A Sociological Modernization Perspective // Voluntas: International Journal of voluntary and nonprofit Organizations, 2003, vol. 14, no. 2, pp. 167-187.

22. Lainé M. Can Culture Account for Investment Expectations? // Journal of Economic Issues, 2016, vol. 50, no. 1, pp. 72-94.

23. Lankoski L., Smith N., Van Wassenhove L. Stakeholder Judgments of Value // Business Ethics Quarterly, 2016, vol. 26, no. 2, pp. 227-256.

24. North D. Economic Performance Through Time // American Economic Review, 1994, vol. 84, no. 3, pp. 359-367.

25. Prisching M. Understanding inescapable modernization: Werner Sombart and Joseph Schumpeter // Journal of Evolutionary Economics, 2015, vol. 25, no. 1, pp. 185-196.

26. Simon H.A. Rationality in Psychology and Economics // The Journal of Business. 1986, vol. 59, no. 4, pp. 2. Behavioral Foundations of Economic Theory, pp. S209-S224. 
27. Tauheed L.F. A Critical Institutionalist Reconciliation of "Contradictory" Institutionalist Institutions: Institutions and Social Provisioning // Journal of Economic Issues, 2013, vol. 47, no. 4, pp. 827-854.

28.Zalewski D.A. Collective Action and Economic Justice: A Structural Approach // Journal of Economic Issues, 2014, vol. 48, no. 2, pp. 493500.

29.Zweynert J. Germany after World War II and contemporary Russia // Eastern Economic Journal, 2006, vol. 32, no. 3, pp. 457-478.

\section{References}

1. Borisova E., Kul'kova A. Kul'tura, imena i ekonomicheskoe razvitie [Culture, names and economic development]. Voprosy ekonomiki, 2016, no. 1, pp. 81-106.

2. Bulgakov S.N. Pravoslavie. Ocherki ucheniya pravoslavnoy tserkvi [Orthodoxy. Essays on the doctrine of the Orthodox Church]. M.: Terra, $1991.416 \mathrm{p}$.

3. Zimin A.A., Horoshkevich A.L. Rossiya vremeni Ivana Groznogo [Russia of the Time of Ivan the Terrible]. M.: Nauka, 1982. 184 p.

4. Inshakov O.V., Frolov D.P. Evolyutsiya institutsionalizma $v$ rossiyskoy ekonomicheskoy mysli ( $I X-X X I v v$.) [Institutionalism evolution in the Russian economic thinking (IX-XXI centuries)]. Vol. 1. Moscow: Ekonomist", 2007. $511 \mathrm{p}$.

5. Kartashev A.V. Tserkov', istoriya, Rossiya: stat'i $i$ vystupleniya [Church, history, Russia: articles and speeches]. M.: Probel, 1996. pp. 155-167.

6. Kozlovski P. Printsipy eticheskoy ekonomii [Principles of ethical economics]. SPb.: Ekonomicheskaya shkola, 1999. 344 p.

7. Kostomarov N.I. Ocherk domashney zhizni i nravov velikorusskogo naroda v XVI i XVII stoletiyakh [Essay on domestic life and customs of the Great Russian people in the 16th and 17th centuries]. SPb.: Tipografiya K. Vul'fa, 1860. $215 \mathrm{p}$.

8. Mitropolit Smolenskiy i Kaliningradskiy Kirill, Russkaya pravoslavnaya tserkov'v sovremennoy Rossii: sluzhenie obshchestvu, trudnosti vozrozhdeniya [Russian Orthodox Church in modern Russia: ser- 
vice to society, difficulties of revival]. Voprosy ekonomiki. 2002. № 1, pp. 23-31.

9. Rukovodstvo po sotsial'noy otvetstvennosti. GOST R ISO 26000-2012. Izdanie ofitsial'noe [Guidance on social responsibility. ISO 260002012. Official edition]. M.: Standartinform, 2014. 126 p.

10. Trubetskoy H.S. Izbrannoe [Selected works]. M.: ROSSPEN, 2010. $616 \mathrm{p}$.

11. Federal'nyy zakon ot 11.06.2003 N 74-FZ «O krest'yanskom (fermerskom) khozyaystve» [Federal Law 11.06.2003 N 74-FZ "On the Peasant (Fermented) Economy"]. http://www.consultant.ru/document/ cons_doc_LAW_42662/

12. Shulimova A.A. Model' sotsial'no orientirovannoy rynochnoy ekonomiki v ekonomicheskom uchenii russkoy pravoslavnoy tserkvi [The model of socially-oriented market economy in the economic doctrine of the Russian Orthodox Church]. Razvitie sotsial'noy sfery: regional'nyy vzglyad [Development of the social sphere: regional perspective]. Krasnodar: IEE MISS 2008, pp. 133-137.

13. Shulimova A.A. Pravoslavnaya etika khozyaystvovaniya i «dukh sotsi-al'nogo kapitalizma» [The Orthodox ethics of management and the "spirit of social capitalism"]. Sotsial'no-gumanitarnyy vestnik: Vserossiyskiy sbornik nauchnykh statey. Krasnodar, 2010, pp. 104-110.

14. Ekonomicheskie issledovaniya: analiz sostoyaniya i perspektivy razvitiya [Economic research: analysis of the state and development prospects] / O.I. Kirikov (Ed.). Voronezh: VGPU, 2007, pp. 70-78.

15. Adkisson R.V. Quantifying Culture: Problems and Promises. Journal of Economic Issues, 2014, vol. 48, no. 1, pp. 89-108.

16. Ambrosino A.A. Cognitive Approach to Law and Economics: Hayek's Legacy. Journal of Economic Issues, 2014, vol. 48, no. 1, pp. 19-48.

17. Coleman S. Economy and religion. A Handbook of Economic Anthropology / J.G. Carrier (Ed.), Cheltenham: Edward Elgar, 2005, pp. 339352.

18. Dequech D. Logics of Action, Provisioning Domains, and Institutions: Provisioning Institutional Logics. Journal of Economic Issues, 2013, vol. 47, no. 1, pp. 95-112. 
19. Frolov D.P., Shulimova A.A. The evolution of socio-responsible business in developing countries: an institutional perspective. Life Science Journal, 2014, vol. 11, no. 11, pp. 562-566.

20. Hodgson G.M. The evolution of morality and the end of economic man. Journal of Evolutionary Economics, 2014, vol. 24, no. 1, pp. 83-106.

21. Hustinx L., Lammertyn F. Collective and Reflexive Styles of volunteering: A Sociological Modernization Perspective. Voluntas: International Journal of voluntary and nonprofit Organizations, 2003, vol. 14, no. 2, pp. 167-187.

22. Lainé M. Can Culture Account for Investment Expectations? Journal of Economic Issues, 2016, vol. 50, no. 1, pp. 72-94.

23. Lankoski L., Smith N., Van Wassenhove L. Stakeholder Judgments of Value. Business Ethics Quarterly, 2016, vol. 26, no. 2, pp. 227-256.

24. North D. Economic Performance Through Time. American Economic Review, 1994, vol. 84, no. 3, pp. 359-367.

25. Prisching M. Understanding inescapable modernization: Werner Sombart and Joseph Schumpeter. Journal of Evolutionary Economics, 2015, vol. 25, no. 1, pp. 185-196.

26. Simon H.A. Rationality in Psychology and Economics. The Journal of Business. 1986, vol. 59, no. 4, pp. 2. Behavioral Foundations of Economic Theory, pp. S209-S224.

27. Tauheed L.F. A Critical Institutionalist Reconciliation of "Contradictory" Institutionalist Institutions: Institutions and Social Provisioning. Journal of Economic Issues, 2013, vol. 47, no. 4. pp. 827-854.

28. Zalewski D.A. Collective Action and Economic Justice: A Structural Approach. Journal of Economic Issues, 2014, vol. 48, no. 2, pp. 493-500.

29.Zweynert J. Germany after World War II and contemporary Russia. Eastern Economic Journal, 2006, vol. 32, no. 3. pp. 457-478.

\section{ДАННЫЕ ОБ АВТОРЕ}

Шулимова Анна Анатольевна, доцент кафедры «Экономическая теория», кандидат экономических наук Кубанский государственный аграрньй университет имени И.Т. Трубилина 
ул. Калинина, 13, г. Краснодар, Краснодарский край, 350044, Российская Федераичия shulimova.a@kubsau.ru

\section{DATA ABOUT THE AUTHOR}

Shulimova Anna Anatolievna, Associate Professor, «Economic Theory», Candidate of Economic Sciences

Kuban State Agrarian University named after I.T. Trubilin 13, Kalinina Str., Krasnodar, 350044, Russian Federation shulimova.a@kubsau.ru SPIN-code: 9107-4268 ORCID: 0000-0001-6373-136X ResearcherID: B-8297-2018 Scopus Author ID: 56275712900 